\title{
Study on preferred method of optimizing polymer molecular weight
}

\section{Zeng Yongying}

\author{
No.5 Production Plant, Daqing Oilfield Company Limited, P.R.China
}

Keywords: polymer molecular weight, inaccessible pore volume,Simulation

\begin{abstract}
In this paper, a new method is proposed to optimize the molecular weight of polymer based on the analysis of the influence of polymer molecular weight on oil displacement, which is by using the method of the pore volume, the parameters of polymer flooding and permeability, the numerical simulation. Not only the pore size of polymer molecules was considered, but also the matching of polymer molecular weight and permeability has been taken into account, Simulation of single molecular weight and different molecular weight optimal combination is carried out, and the results show that the method can improve polymer flooding effect by enlarging the sweep volume, and improve the economic efficiency of polymer flooding too.
\end{abstract}

\section{Introduction}

The effect of polymer flooding is not only related to the geological conditions of the reservoir, but also one of the important factors affecting the polymer flooding effect. The molecular weight of polymer plays an important role in polymer flooding.

Polymer flooding is to increase oil recovery by increasing the viscosity of injected water and decreasing the permeability of water phase. The molecular weight of polymer is one of the main parameters that affect the above mechanism. The higher molecular weight of the polymer, the better the viscosity, and the stronger the ability to reduce the water permeability[1]. The results of physical simulation experiments show that the higher the molecular weight of the polymer is, the higher the recovery rate is . The results show that when the polymer concentration is $1000 \mathrm{mg} / \mathrm{L}$, the molecular weight of the polymer is 5 million, the viscosity is $17 \mathrm{mPa}$.s and the residual resistance coefficient is about 1.8,while when the molecular weight of the polymer is 17 million, the viscosity is $47 \mathrm{mPa}$.s and the residual resistance coefficient is about 4.6 , and the enhanced oil recovery up to $18.5 \%$ (Tab.1).So, the dosage of high molecular weight polymers is less than that of low molecular weight polymers. And the higher of enhanced oil recovery.Therefore, Due to the price is close of different molecular weight,in the case of geological conditions and injection conditions permission, a high molecular weight polymer should be choosen, in order to achieve better effect of polymer flooding under the same conditions.

Tab.1 Residual resistance coefficient and oil recovery of different molecular weight polymers

\begin{tabular}{|c|c|c|c|c|}
\hline $\begin{array}{c}\text { molecular weight } \\
\text { (million) }\end{array}$ & $\begin{array}{c}\text { concentration } \\
(\mathrm{mg} / \mathrm{L})\end{array}$ & $\begin{array}{c}\text { viscosity } \\
(\mathrm{mPa} . \mathrm{s})\end{array}$ & $\begin{array}{c}\text { Residual resistance } \\
\text { coefficient }\end{array}$ & enhanced oil recovery (\%) \\
\hline 5 & 1000 & 17 & 1.8 & 10.6 \\
\hline 10 & 1000 & 33 & 2.4 & 14.3 \\
\hline 17 & 1000 & 47 & 4.6 & 18.5 \\
\hline
\end{tabular}

\section{Method Of How To Optimize Polymer Molecular Weight}

Optimization of the molecular weight with inaccessible pore volume. When the polymer solution flows through the porous medium, it is naturally chosen by the pore throat size of the rock, In this paper, the boundary occupied bound water pores as polymer molecules do not enter the molecular size to IPV=Swi(inaccessible pore volume is shorted for IPV)corresponding to the water as the compatibility of polymer molecules and rock and pore throat size[2].

With the increase of the molecular size and molecular weight of the polymer, the IPV increases almost linearly(Fig.1). The size of IPV reflects the compatibility of polymer molecules and pore 
throat size. The rock permeability is certain, if molecular size selection is too large, the liquidity clew is poor, easily trapped in a narrow channel at the residence, around injection wells polymer mechanical trapping volume increases, the loss in the early polymer injection process,fhe injection efficiency and the effectiveness of the polymer in the oil reservoir are influenced[3],Instead, if the molecular size is too small, the polymer viscosity is low, and the solution is easy to follow the large pore flow in the high permeable layer.

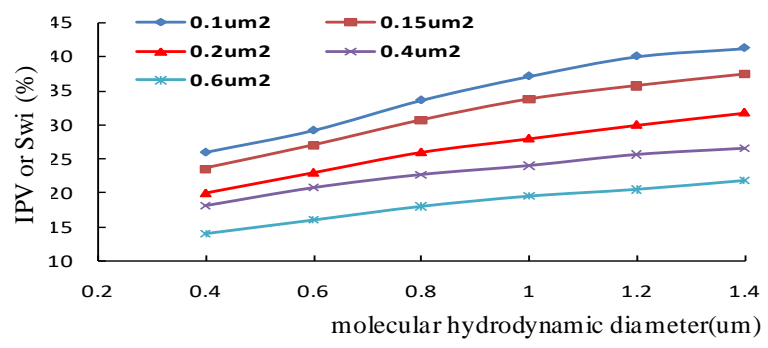

Fig.1 Relationship between molecular hydraulic diameter and IPV of different permeability reservoirs

Using the figure 1, we could select the molecular hydraulic diameter of different permeability reservoir and different pore volume,then the molecular hydrodynamic diameter was added to the molecular weight in Figure 2.For example,oilfield A, Swi=26.05\%, so IPV=26.05\%, permeability $=0.2 \mathrm{um} 2$, In Figure 1, the molecular hydrodynamic diameter of the block is 1.0um, The molecular hydrodynamic diameter 1.0um was added to figure 2 and the molecular weight was 1200 x 104.



Fig. 2 Molecular hydrodynamic diameters of polymers with different molecular weights

Optimization of the molecular weight with reservoir properties and polymer parameters . In order to ensure that the polymer system has good matching with the oil layers with different permeability levels[4], according to the relationship between polymer flooding parameters and reservoir properties(Tab.2), reservor with Permeability of $0.1 \mathrm{um} 2$ can be injected into the polymer system of 7 million molecular weight, concentration less than $1500 \mathrm{mg} / \mathrm{L}$.and reservor with Permeability of $0.3 \mathrm{um} 2$ can be injected into the polymer system of 25 million molecular weight, concentration less than $2000 \mathrm{mg} / \mathrm{L}$. For example,oilfield A, permeability=0.2um2, In Tab2, the highst molecular weight was 1700 x 104 .the highest concentration was $2000 \mathrm{mg} / \mathrm{L}$.

Tab.2 Relationship between polymer flooding parameters and reservoir properties

\begin{tabular}{|c|c|c|c|c|c|}
\hline permeability & concentration & & molecu & $s\left(x 10^{4}\right)$ & \\
\hline$\left(\mu \mathrm{m}^{2}\right)$ & $(\mathrm{mg} / \mathrm{L})$ & 700 & 1200 & 1700 & 2500 \\
\hline \multirow{3}{*}{0.05} & 1000 & difficult & difficult & blocking & blocking \\
\hline & 1500 & difficult & blocking & blocking & blocking \\
\hline & 2000 & blocking & blocking & blocking & blocking \\
\hline \multirow{3}{*}{0.1} & 1000 & easy & able & difficult & blocking \\
\hline & 1500 & able & difficult & difficult & blocking \\
\hline & 2000 & difficult & difficult & blocking & blocking \\
\hline \multirow{3}{*}{0.2} & 1000 & easy & easy & able & able \\
\hline & 1500 & easy & able & able & able \\
\hline & 2000 & able & able & able & difficult \\
\hline
\end{tabular}




\begin{tabular}{|c|c|c|c|c|c|}
\hline permeability & concentration & \multicolumn{5}{|c|}{ molecular weights $\left(\mathrm{x} 10^{4}\right)$} \\
\hline \multirow{3}{*}{0.3} & $(\mathrm{mg} / \mathrm{L})$ & 700 & 1200 & 1700 & 2500 \\
\hline & 1000 & easy & easy & easy & easy \\
\cline { 2 - 6 } & 1500 & easy & easy & easy & able \\
\cline { 2 - 6 } & 2000 & easy & easy & able & able \\
\hline
\end{tabular}

\section{Optimization of polymer molecular weight by numerical simulation.}

1. Mathematical model of polymer molecular weight.The viscosity curves, pore volume, molecular adsorption and shear parameters are mainly considered.

viscosity curve: $\mu_{\mathrm{p}}^{0}=\mu_{\mathrm{w}}\left(1+\left(A_{\mathrm{p} 1} C_{\mathrm{p}}+A_{\mathrm{p} 2} C_{\mathrm{p}}^{2}+A_{\mathrm{p} 3} C_{\mathrm{p}}^{3}\right) C_{\mathrm{SEP}}^{\mathrm{S}_{\mathrm{p}}}\right)$

rheological characteristics: $\quad \mu_{\mathrm{p}}=\mu_{\mathrm{w}}+\frac{\mu_{\mathrm{p}}^{0}-\mu_{\mathrm{w}}}{1+\left(\gamma / \gamma_{\text {ref }}\right)^{\mathrm{p}_{\alpha}-1}}$

Permeability decreasing coefficient : $\quad R_{\mathrm{k}}=1+\frac{\left(R_{\mathrm{KMAX}}-1\right) b_{\mathrm{rk}} C_{\mathrm{p}}}{1+b_{\mathrm{rk}} C_{\mathrm{p}}}$

2. Numerical simulation of polymer flooding with different molecular weights. The effect of different molecular weight on polymer flooding was predicted by the injection concentration $1200 \mathrm{mg} / \mathrm{L}$, injection rate $0.2 \mathrm{PV} / \mathrm{a}$ and polymer dosage $1200 \mathrm{mg} / \mathrm{L.PV}$. From the numerical simulation results, with the increasing of molecular weight, the lower the value of water cut, the higher the stage of water cut, the higher the stage of recovery(Tab.3), but the lower the injection ability.

Tab. 3 Prediction of polymer flooding effect with different molecular weights in oilfield A

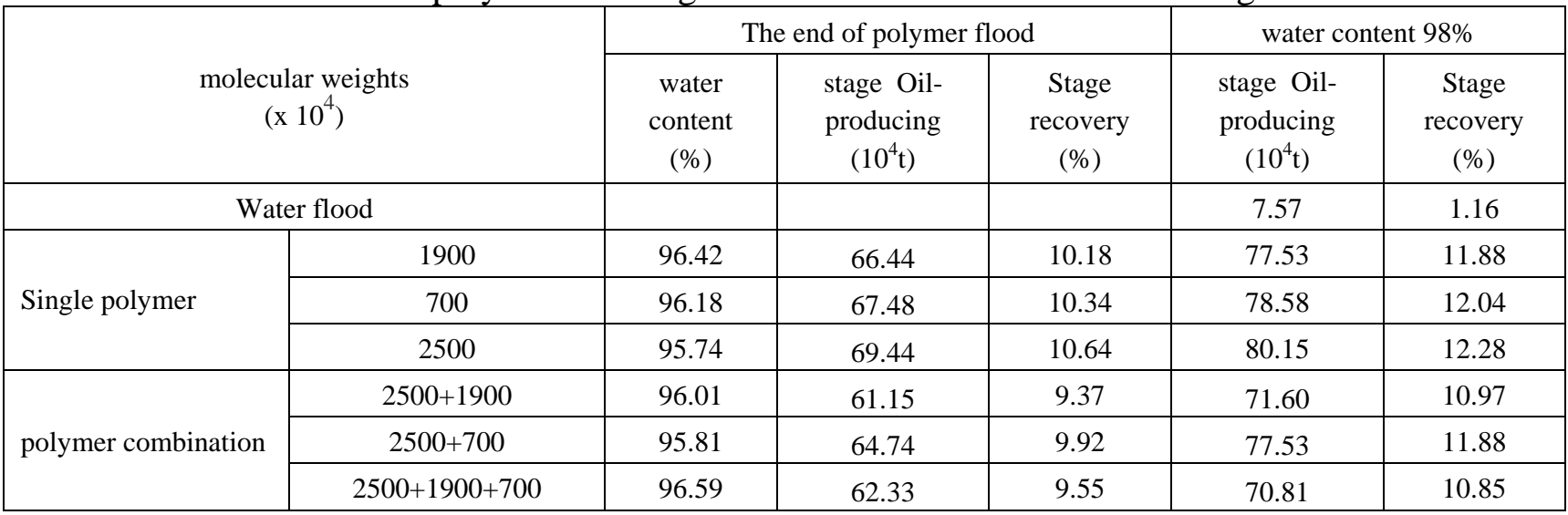

Considering the injection condition in the actual injection process, different molecular weights are combined in the same injection parameters.From the results of numerical simulation , Combination of 25 million and 7 million molecular weight will get the highest recovery.

\section{Conclusion}

(1) The pore volume of the reservoir can be determined by the water saturation, and the molecular weight of the polymer can be determined according to the molecular weight hydraulic diameter of the pore volume of different permeability reservoirs.

(2) The relationship between polymer flooding parameters and reservoir properties can not only determine the molecular weight of polymer, but also optimize the concentration of polymer.

(3) Numerical simulation not only can be used to optimize the single molecular weight of polymers, but also can optimize the best combination of different polymers

\section{Reference}

[1] Xu Jianjun, Xu Yan-chao, Yan, Li-me,et.al. Research on the method of optimal PMU placement. International Journal of Online Engineering,v9, S7, p24-29, 2013 
[2] Xu Jian-Jun,Y. Y. Zi.,Numerical Modeling for Enhancement of Oil Recovery via Direct Current. International Journal of Applied Mathematics and Statistics,2013,43(13):318-326

[3] Longchao, Zhu Jianjun, Xu; Limei, Yan. Research on congestion elimination method of circuit overload and transmission congestion in the internet of things. Multimedia Tools and Applications, p 1-20, June 27, 2016

[4] Yan Limei, Zhu Yusong, Xu Jianjun,et.al. Transmission Lines Modeling Method Based on Fractional Order Calculus Theory. TRANSACTIONS OF CHINA ELECTROTECHNICAL SOCIETY, 2014 ,Vol.29,No. 9:260-268 (In Chinese)

[5] YAN Li-mei, CUI Jia, XU Jian-jun,et.al. Power system state estimation of quadrature Kalman filter based on PMU/SCADA measurements. Electric Machines and Control. 2014, Vol.18 No.6,: 78-84. (In Chinese)

[6] YAN Limei,XIE Yibing, XU Jianjun, et.al. Improved Forward and Backward Substitution in Calculation of Power Distribution Network with Distributed Generation. JOURNAL OF XI'AN JIAOTONG UNIVERSITY,2013, Vol.47, No.6, p117-123. (In Chinese)

[7] Xu J.J., Gai D., Yan L.M. A NEW FAULT IDENTIFICATION AND DIAGNOSIS ON PUMP VALVES OF MEDICAL RECIPROCATING PUMPS. Basic \& Clinical Pharmacology \& Toxicology, 2016,118 (Suppl. 1), 38-38 